\title{
Synergistic effects of sepiolite on intumescent flame retardant polypropylene
}

\author{
N. H. Huang ${ }^{1,2^{*}}$, Z. J. Chen ${ }^{1,2}$, J. Q. Wang 3 , P. Wei ${ }^{4}$ \\ ${ }^{1}$ Key Laboratory of Green Processing and Functional Textiles of New Textile Materials, Ministry of Education, Wuhan \\ Textile University, Wuhan 430073, China \\ ${ }^{2}$ Department of Polymer Science and Engineering, Wuhan Textile University, Wuhan 430073, China \\ ${ }^{3}$ National Laboratory of Flame Retardant Materials, Beijing Institute of Technology, Beijing 100081, China
}

Received 11 May 2010; accepted in revised form 17 August 2010

\begin{abstract}
In this paper, the effects of sepiolite as a synergistic agent on the flame retardancy of intumescent flame retardant polypropylene (PP/IFR) were studied using the limiting oxygen index (LOI), the UL-94 test, thermogravimetric analysis (TGA), laser Raman spectroscopy (LRS), cone calorimeter test (CCT) and scanning electron microscopy (SEM), and the IFR system mainly consisted of the ammonium polyphosphate modified with $\gamma$-aminopropyltriethoxysilane coupling agent, melamine and dipentaerythritol. The results from the LOI and UL 94 tests show that sepiolite added to the PP/IFR system has a synergistic flame retardant effects with the IFR system. The TGA results reveal that sepiolite enhances the thermal stability of the PP/IFR composite and increases the char residue formation. The cone calorimeter results indicate that the heat release rate, mass loss rate, total heat release and average specific extinction area of the PP/IFR/sepiolite composite decrease in comparison with the PP/IFR composite. The LRS measurements provide useful information on the carbonaceous microstructures. The morphological structures observed by SEM have demonstrated that sepiolite promote the formation of the reinforced and homogeneous char barrier on the surface of the composites. Simultaneously, the Young's modulus and flexural modulus of the PP/IFR composites are also much better improved with the increase of sepiolite added.
\end{abstract}

Keywords: polymer composites, sepiolite, polypropylene, intumescent flame retardant, synergistic effect

\section{Introduction}

Polypropylene (PP) is an important commodity plastic and used extensively in many fields, such as housing, transportation, and electrical engineering materials, but its usage is often limited because of its poor flame retardancy (the limiting oxygen index (LOI) is often lower than 18\%). Therefore, studies on flame-retardant PP have attracted considerable interest during the last decades. One of the most important ways to improve the fire retardancy of PP is by applying an intumescent flame retardant (IFR) [1-5]. On heating, the IFR additives form a foamed cellular charred layer on the surface of the product, which slows down the heat and mass transfer between the gas and the condensed phase. Moreover, the IFR systems reduce the smoke density and produce little corrosive gas during combustion.

However, the IFR systems are relatively effective at low concentrations but not enough in stringent cases. In order to enhance the flame retardancy, new intumescent flame retardant systems have been developed rapidly [3, 6-8], which has high flame retardant efficiency. In addition, some synergistic agents have also been used to improve further the flame retardant of intumescent flame retardant PP systems, such as nano- $\mathrm{Mn}_{0.4} \mathrm{Zn}_{0.6} \mathrm{Fe}_{2} \mathrm{O}_{4}$ [9], zeolites [10], montmorillonite [11, 12], silica [13], 
alumina [13], silicotungstic acid [14], lanthanum oxide [15, 16], nano- $\mathrm{BaWO}_{4}$ [17], expandable graphite [18], iron powder [19], nanoflaky manganese phosphate [20], phosphotungstic acid [21], hydroxy silicone oil [22], a-ZrP [23], colemanite [24], zinc borate [25], polysilsesquioxane [26], borosiloxane [27] and other metallic compounds [1]. Sepiolite is a family of fibrous hydrated magnesium silicate with the theoretical half unit-cell formula $\mathrm{Si}_{12} \mathrm{O}_{30} \mathrm{Mg}_{8}(\mathrm{OH})_{4}\left(\mathrm{OH}_{2}\right)_{4} \cdot 8 \mathrm{H}_{2} \mathrm{O}$ characterized by a needle-like morphology [28]. It can have a surface area as high as $200-300 \mathrm{~m}^{2} / \mathrm{g}$, lengths of $0.2-4 \mu \mathrm{m}$, a width of $10-30 \mathrm{~nm}$ and thickness of $5-10 \mathrm{~nm}$ [29]. In a previous study, we found that sepiolite has a good flame retardant synergistic effect with magnesium hydroxide in EVA [30] or PP [31]. However, there are few reports about sepiolite use in IFR polypropylene [32, 33].

In general, the poor water resistance and compatibility with PP matrix of traditional IFR system based on ammonium polyphosphate (APP), melamine and pentaerythritol restrict its application. Demir et al. [34] found that surface modification of APP with 3-(trimethoxysilyl)-1-propanethiol coupling agent can improve its water resistance and the compatibility. So, the IFR system based on APP modified with $\gamma$-aminopropyltriethoxysilane coupling agent was used as flame retardant in this paper.

The objective of this paper is to study the synergistic effects of sepiolite with the IFR system based on ammonium polyphosphate (IFR) modified with $\gamma$-aminopropyltriethoxysilane coupling agents, melamine and dipentaerythritol in PP using the limiting oxygen index (LOI), UL-94 test, thermogravimetric analysis(TGA), cone calorimeter test, Raman spectroscopy, and scanning electron microscopy (SEM). Mechanical properties of the composites have also been tested. More detailed investigations concerning the thermal degradation mechanism of PP/IFR/sepiolite composite are still ongoing by using in situ FTIR, TG/FTIR, Py-GC-MS and XPS techniques in the lab.

\section{Experimental}

\subsection{Materials}

Polypropylene powder (PP) (PPH-XD-075, melt flow rate: $2.1 \mathrm{~g} / 10 \mathrm{~min}, 230^{\circ} \mathrm{C}, 2.16 \mathrm{~kg}$ ), with the particle size $140-240 \mu \mathrm{m}$, was purchased from Wuhan Petroleum Chemical Plant, China. The intu- mescent flame retardant system containing $22 \pm 2 \mathrm{wt} \% \mathrm{P}, 18 \pm 1 \mathrm{wt} \% \mathrm{~N}$ with an average particle size of $10 \mu \mathrm{m}$, which consisted of ammonium polyphosphate modified with $\gamma$-aminopropyltriethoxysilane coupling agent (APP), melamine (MN) and dipentaerythritol (DPER) (the mass ratio of APP, MN and DPER is 4:1:1), was purchased from Hangzhou JLS Flame Retardants Chemical Co., Ltd., China. Non-modified Pangel S9 sepiolite was kindly supplied by Tolsa SA (Spain).

\subsection{Composites preparation}

Prior to mixing and getting the sepiolite dried the sample was heated first at $100^{\circ} \mathrm{C}$ for $4 \mathrm{~h}$ and cooled slowly then to room temperature under vacuum for $16 \mathrm{~h}$. PP matrix composites were firstly prepared by blending of PP, IFR and sepiolite using a highspeed mixer (approximately $1000 \mathrm{r} / \mathrm{min}$ ). Concentration of fillers was fixed at $25 \%$ mass of total amounts of composite. Sepiolite was added with mass fractions of $1,2,3$ and $4 \%$. Then flame retardant PP composites were extruded by a co-rotating twin-screw extruder (diameter $=20 \mathrm{~mm}$, length $/$ diameter $=36$, model: SHJ-20, Lanzhou Tianhua Chemical Engineering and Automation Company, China) at a temperature profile of $130,150,180$, $190,200,205,200^{\circ} \mathrm{C}$, and cutting into pellets using a granulator. The resulting sample bars for testing were prepared by injection moldings (injector: model HBL-1300, Zhejiang Haibo Co., Ltd., China) at a temperature profile of 200,210 and $215^{\circ} \mathrm{C}$.

\subsection{Characterization}

\subsubsection{Limiting oxygen index}

Limiting oxygen index (LOI) measurements were carried out using a JF-3 type instrument (Jiangning Analysis Instrument Factory, China) according to GB 2406-80 (ASTM D 2863-77). The samples used for the test were of dimensions $100 \mathrm{~mm} \times$ $6.5 \mathrm{~mm} \times 3 \mathrm{~mm}$.

\subsubsection{UL-94 test}

The UL-94 vertical test was measured on a CZF-2 type instrument (Jiangning Analysis Instrument Factory, China) with sample dimensions of $127 \mathrm{~mm} \times$ $12.7 \mathrm{~mm} \times 3 \mathrm{~mm}$ according to ASTM D 635-77. UL-94 test results are classified by burning ratings 
$\mathrm{V}-0, \mathrm{~V}-1$ or $\mathrm{V}-2$. $\mathrm{V}-0$ rating presents the best flame retardancy of polymeric materials.

\subsubsection{Thermogravimetric analysis}

Thermogravimetric analysis (TG) was performed on a NETZSCH thermal analyzer (TG 209 F1). Samples weighting about $5.0 \mathrm{mg}$ were heated from room temperature to $700^{\circ} \mathrm{C}$ at a heating rate of $10^{\circ} \mathrm{C} / \mathrm{min}$ in a dynamic nitrogen atmosphere. The nitrogen flow rate was $50 \mathrm{ml} / \mathrm{min}$.

\subsubsection{Cone calorimeter test}

Combustion experiments were performed in a cone calorimeter (Fire Testing Technology, UK) at an incident heat flux of $35 \mathrm{~kW} / \mathrm{m}^{2}$ according to ISO 5600. The bottom and edges of each specimen with a dimension of $100 \mathrm{~mm} \times 100 \mathrm{~mm} \times 4 \mathrm{~mm}$ are wrapped with aluminum foil. All samples were run in duplicate and the average value was reported. Various parameters can be measured including time to ignition (TTI), heat release rate (HRR) as a function of time, peak of heat release rate (PHRR), mass loss rate, and so on. The experimental error of data from the cone calorimeter was about $5 \%$.

\subsubsection{Raman spectroscopy}

The Raman spectra were obtained from a Thermo Fisher Scientific Raman Spectrometer (model DXR) coupled with an OLYMPUS BX51 optical microscope. Excitation wavelengths were $633 \mathrm{~nm}$ using a He-Ne laser. The laser power at the sample was kept below $2 \mathrm{~mW}$ to avoid degradation problems or peak shifts due to overheating effects. The laser was focused to a $2 \mu \mathrm{m}$ diameter spot on the sample using a $50 \times$ objective lens. The spectral resolution was $2 \mathrm{~cm}^{-1}$. The Raman spectra were collected and recorded using a Peltier cooled charge-coupled device (CCD) detector with an exposure time of 30 s. Data (baseline calibration and integral) were processed by the Software 'OMNIC 8.1', Thermo Fisher Scientific Company, USA.

\subsubsection{Scanning electron microscopy}

The SEM micrographs of intumescent chars were observed by a JEOL JSM-7401F scanning electron microscopy. The specimens were previously coated with a conductive gold layer.

\subsubsection{Mechanical properties testing}

The impact strengths were measured with an XJJ-5 Charpy impact tester (Chengde Tester Co., Ltd., China) at $23^{\circ} \mathrm{C}$ according to $\mathrm{GB} / \mathrm{T} 1043$. Tensile tests were carried out on an Instron Universal Tester Machine (model 5566) with a crosshead speed of $50 \mathrm{~mm} / \mathrm{min}$ according to ASTM D 638 . The tested parallel samples were 10 , the presented results are average data.

\section{Results and discussion}

\subsection{LOI and UL 94 testing}

Table 1 presents the changes of LOI values versus sepiolite level for the PP/IFR/sepiolite composites at the total amount of $25 \mathrm{wt} \%$ additives kept constant. It is seen that the LOI value of the PP/IFR composite containing $25 \mathrm{wt} \%$ IFR increases rapidly to 34.4 from $17.6 \%$ of PP, indicating that IFR when used alone can significantly improve flame retardancy of PP. The LOI values of samples (PP0 to PP1) increase to $36.0 \%$ with $1.0 \mathrm{wt} \%$ loading of sepiolite in the formulation. However, the LOI decreases with further addition of sepiolite. When the loading of sepiolite reached to $4 \mathrm{wt} \%$ the LOI value of PP4 decreased to $32.3 \%$. The main reason for this phenomenon may be that, during the combustion process, higher concentration of sepiolite makes the char too rigid and fragile and it increases the heat conductivity.

Table 1. LOI and UL-94 data of PP and its flame retardant composites with different loadings of sepiolite

\begin{tabular}{|l|c|c|c|c|c|c|}
\hline \multicolumn{1}{|c|}{ Sample code } & PP [wt\%] & IFR [wt\%] & SP [wt\%] & LOI & UL 94 test & Dripping \\
\hline PP & 100 & 0 & 0 & 17.6 & no rating \\
\hline PP0 & 75 & 25 & 0 & 34.4 & y-1 & no \\
\hline PP1 & 75 & 24 & 1 & 36.0 & no \\
\hline PP2 & 75 & 23 & 2 & 35.8 & V-0 \\
\hline PP3 & 75 & 22 & 3 & 35.8 & V-1 & no \\
\hline PP4 & 75 & 21 & 4 & 32.3 & V-2 \\
\hline
\end{tabular}


UL-94 test results of the PP/IFR composites versus sepiolite loading are given in Table 1. From Table 1, when the loading of sepiolite was kept in between 1 and $2 \mathrm{wt} \%$ in IFR, and samples of the PP/IFR composites can pass the V-0 rating. However, further increasing to 3 and $4 \mathrm{wt} \%$, they only pass the V-1 rating and V-2 rating as revealed by samples PP3 and PP4, respectively. These results indicate that an appropriate amount of sepiolite may cause the synergistic effect in the PP/IFR/ Sepiolite composites more efficient.

\subsection{Cone calorimeter study}

Cone calorimetry is widely used to evaluate fire performance of materials. Various parameters can be obtained from cone calorimetry including the time to ignition (TTI), the heat release rate (HRR), the peak heat release rate (PHRR), the total heat release (THR), average mass loss rate (av-MLR), average specific extinction area (av-SEA) and fire performance index (FPI) (defined as a ratio of TTI/PHRR) [35], and so on. The heat release rate (HRR) is a very important parameter, and can be used to express the intensity of a fire. An effective flame retardant system normally shows a low HRR value.

The heat release rate curves for PP and its flame retardant PP composites are shown in Figure 1 and all of the cone calorimetric data is presented in Table 2. It can be seen that the pristine PP burns very fast after ignition and a sharp HRR peak appears with a PHRR of $662 \mathrm{~kW} / \mathrm{m}^{2}$. The curve of the PP/IFR composite without sepiolite showed much lower peak heat release rate (PHRR) of $71 \mathrm{~kW} / \mathrm{m}^{2}$, and two peaks are observed at about 63 and $440 \mathrm{~s}$, respectively. According to a former study [20], the first peak could be due to the development of the intumescent protective structure, and the second peak could be assigned to the degradation of this protective layer. In the IFR system, ammonium polyphosphate is used as the acid

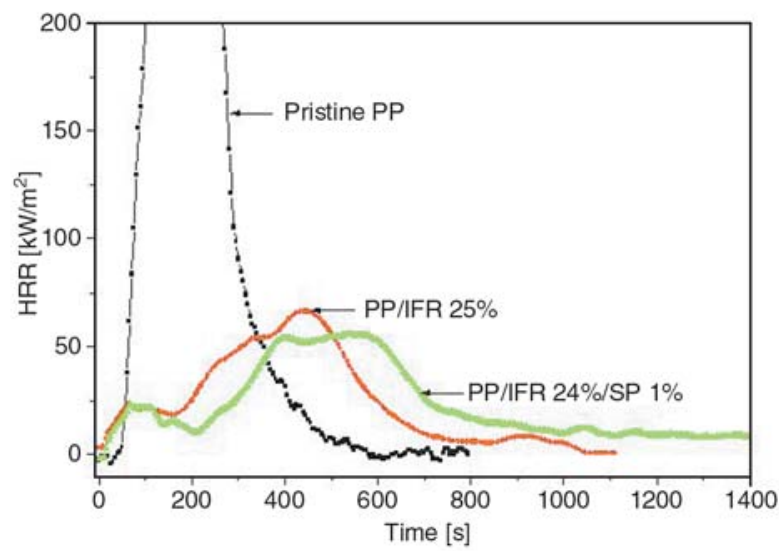

Figure 1. Heat release rate curves for pristine PP, PP/IFR and PP/IFR/SP $1 \%$ composites at a heat flux of $35 \mathrm{~kW} / \mathrm{m}^{2}$

source; during heating, the poly(phosphoric acid) formed in the degradation of APP provides an acid catalyst for organic reactions [36]. During the heating process of APP, gaseous products (mainly ammonia), make the mixture of the phosphor-carbonaceous residue swollen; this leads to the formation of the intumescent char residue. The PHRR values (see Table 2) for PP/IFR composite with $1 \%$ sepiolite was $51 \mathrm{~kW} / \mathrm{m}^{2}$, which was much lower than that for pristine PP $\left(662 \mathrm{~kW} / \mathrm{m}^{2}\right)$ and that for PP/IFR composite $\left(71 \mathrm{~kW} / \mathrm{m}^{2}\right)$. It was also noteworthy that the HRR curve for PP/IFR/SP $1 \%$ composite exhibited a flattened pattern at $400-600 \mathrm{~s}$, as shown in Figure 1. This was probably because sepiolite enhanced the strength and thermal stability of char layer, prevented the char layer from cracking and promoted the formation of the homogenous and compact intumescent char layer (see the SEM micrographs to be presented later). It was also found that IFR and sepiolite obviously render the ignition time shortened (see Table 2) which is attributed to the char layer formation on the surface of the PP/IFR composites. This is because the char layer prevents heat and oxygen from transferring into the matrix interior [16]. At the initial stage of heating, the surface temperature of the PP/IFR and $\mathrm{PP} / \mathrm{IFR} / \mathrm{SP}$ composites rises quickly due to the char

Table 2. Cone summary results of pristine PP and its flame retardant composites $\left(35 \mathrm{~kW} / \mathrm{m}^{2}\right)$

\begin{tabular}{|c|c|c|c|c|c|c|}
\hline Sample & TTI [s] & PHRR $\left[\mathrm{kW} / \mathrm{m}^{2}\right]$ & THR [MJ/m²] & av-SEA $\left[\mathrm{m}^{2} / \mathrm{kg}\right]$ & av-MLR $\left[\mathrm{g} / \mathrm{s} \cdot \mathrm{m}^{2}\right]$ & FPI $\left[\mathrm{kW} / \mathrm{m}^{2} \cdot \mathrm{s}\right]$ \\
\hline Pristine PP & 48 & 662 & 83.3 & 487.8 & 0.040 & 0.073 \\
\hline PP/IFR 25\% & 30 & 71 & 32.5 & 348.2 & 0.012 & 0.423 \\
\hline PP/IFR 24\%/SP $1 \%$ & 29 & 51 & 30.8 & 238.9 & 0.009 & 0.569 \\
\hline
\end{tabular}

TTI, time to ignition; PHRR, peak heat release rate; THR, total heat release; av-SEA, average specific extinction area; av-MLR, average mass loss rate; FPI, fire performance index 


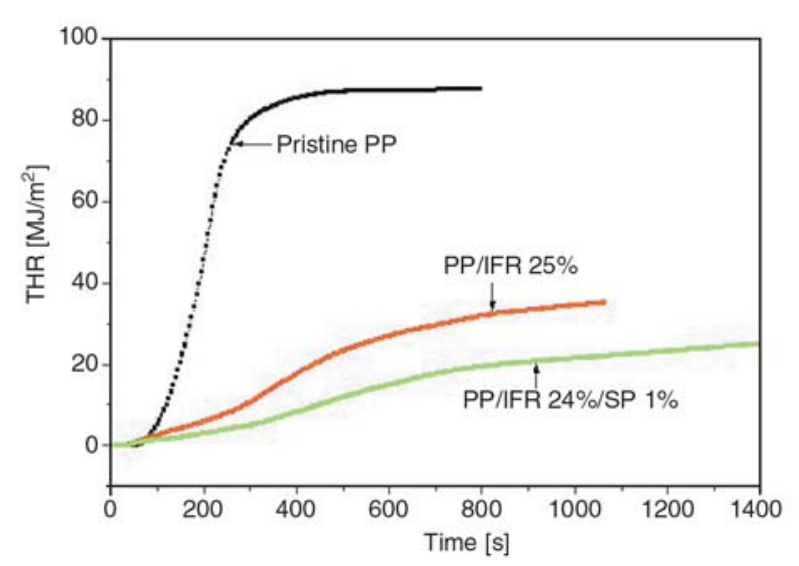

Figure 2. Total heat release (THR) curves for pristine PP, $\mathrm{PP} / \mathrm{IFR}$ and PP/IFR/SP $1 \%$ composites at a heat flux of $35 \mathrm{~kW} / \mathrm{m}^{2}$

layer formation, this results in fast decomposition of PP on the surface of the composites. Therefore, this makes the ignition time (TTI) shortened.

Figure 2 shows another plot for total heat release (THR) of all samples. Similar conclusion can be drawn that the THR goes down while the flame retardant IFR and IFR/SP were incorporated in. Consequently, it is also suggested that the synergistic effect between IFR and sepiolite is well deserved in the system.

Fire performance index (FPI) is independent of the tested sample thickness and often used to predict whether a material can easily develop drastic combustion after ignition. Therefore, the smaller the FPI value is, the better the fire resistance is. From Table 2, PP/IFR/SP 1\% composite has the smallest value of 1.76 , indicating that sepiolite can improve the flame retardant efficiency of PP/IFR composite. In addition, it clearly shows that both the smoke emission and average mass loss rate during combustion process are depressed by the incorporation of sepiolite.

\subsection{Thermogravimetric analysis}

Figures 3 and 4 present TG and DTG curves of pristine $\mathrm{PP}, \mathrm{PP} / \mathrm{IFR}$, and $\mathrm{PP} / \mathrm{IFR} / \mathrm{SP} 1 \%$ samples under a flow of $\mathrm{N}_{2}$, respectively. The $10 \%$ mass loss

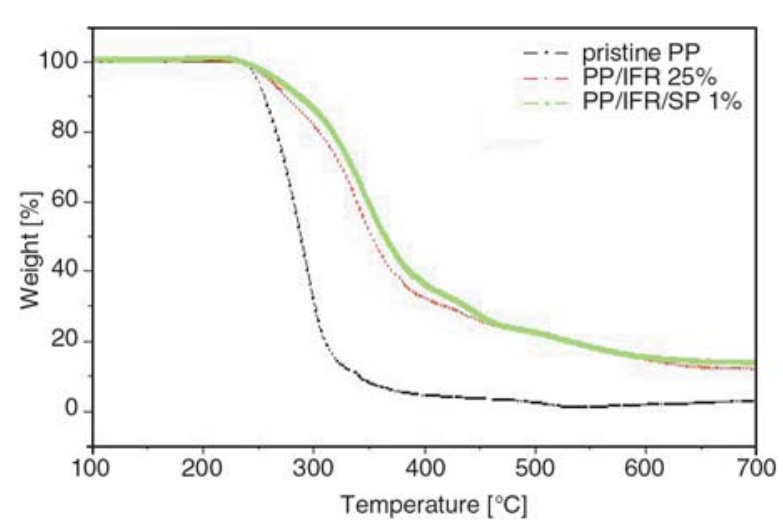

Figure 3. TG curves of pristine PP, PP/IFR and $\mathrm{PP} / \mathrm{IFR} / \mathrm{SP} 1 \%$ composites in $\mathrm{N}_{2}$ at a heating rate of $10^{\circ} \mathrm{C} / \mathrm{min}$

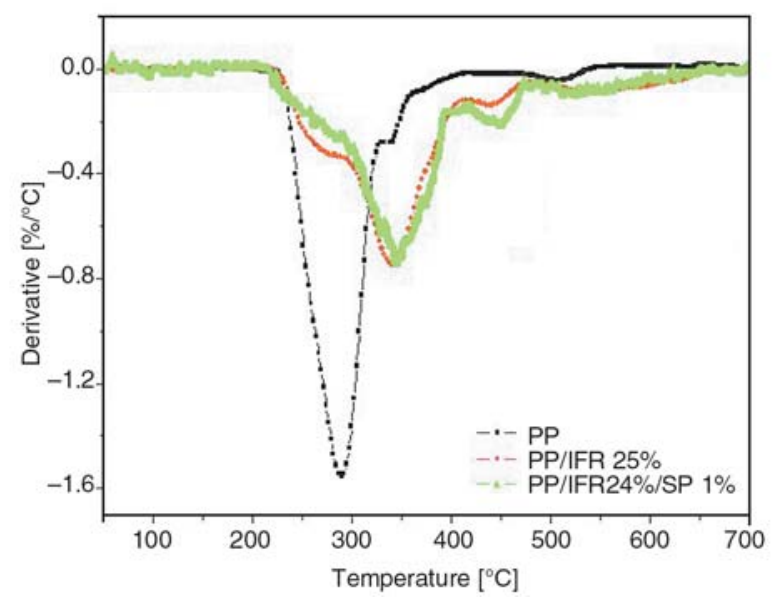

Figure 4. DTG curves of pristine PP, PP/IFR and $\mathrm{PP} / \mathrm{IFR} / \mathrm{SP} 1 \%$ composites in $\mathrm{N}_{2}$ at a heating rate of $10^{\circ} \mathrm{C} / \mathrm{min}$

temperature $\left(T_{10 \%}\right)$, the maximum mass loss temperature $\left(T_{\max }\right)$, the maximum mass loss rate $\left(R_{\max }\right)$, and char (or residue) yield values at $700^{\circ} \mathrm{C}$ are all summarized in Table 3. PP loses the weight in the temperature range $249-350^{\circ} \mathrm{C}$, formation a residue of about $2.7 \%$ at $700^{\circ} \mathrm{C}$. It is clearly seen from Table 3 that the onset temperature (temperature at $10 \%$ mass loss, $T_{10 \%}$ ) is increased for all composites, by $23^{\circ} \mathrm{C}$ for PP/IFR composite and $33^{\circ} \mathrm{C}$ for PP/IFR/SP $1 \%$ composite, respectively. The above results indicate that sepiolite improves the thermal stability of PP/IFR composite. However, this does

Table 3. TGA data of pristine PP, PP/IFR and PP/IFR/SP $1 \%$ samples under $\mathrm{N}_{2}$ at a heating rate of $10^{\circ} \mathrm{C} / \mathrm{min}$

\begin{tabular}{|l|c|c|c|c|}
\hline \multicolumn{1}{|c|}{ Sample } & $\mathbf{T}_{\mathbf{1 0} \%}\left[{ }^{\circ} \mathbf{C}\right]$ & $\mathbf{T}_{\max }\left[{ }^{\circ} \mathbf{C}\right]$ & $\mathbf{R}_{\max }[\boldsymbol{\%} / \mathbf{m i n}]$ & Residue yield at $_{\mathbf{7 0 0}}{ }^{\circ} \mathbf{C}[\mathbf{w t} \%]$ \\
\hline Pristine PP & 255 & 295 & 1.55 & 2.7 \\
\hline PP/IFR & 278 & 340 & 0.75 & 11.8 \\
\hline PP/IFR/SP 1\% & 288 & 347 & 0.73 & 13.9 \\
\hline
\end{tabular}

$T_{10 \%}$ is the temperature at $10 \%$ weight loss; $T_{\max }$ is the temperature at which the rate of weight loss reaches a maximum. $R_{\max }$ is the maximum rate of weight loss. 
notcorrelate with a decrease of TTI in the cone calorimeter (see Table 2). The fact may be attributed to the existence of sepiolite which may cause the whole process more complicated.

The IFR made a profound effect on the maximum thermal decomposition temperature $\left(T_{\max }\right)$. It can be seen from Table 3 that with the IFR obviously enhanced $T_{\max }$ of PP, which is $295^{\circ} \mathrm{C}$ for pristine $\mathrm{PP}, 340^{\circ} \mathrm{C}$ for the $\mathrm{PP} / \mathrm{IFR}$ composite and $347^{\circ} \mathrm{C}$ for the PP/IFR/SP $1 \%$ composite, respectively. This fact demonstrated that the char layer formed at higher temperature protected PP from decomposing. The maximum mass loss rate $\left(R_{\max }\right)$ for PP/IFR composite with and without sepiolite are decreased from 1.55 to $0.75,0.73 \% /{ }^{\circ} \mathrm{C}$, respectively. It is noteworthy that the char residue of pristine $\mathrm{PP}$ and PP/IFR composite are only 2.7 and $11.8 \mathrm{wt} \%$ at $700^{\circ} \mathrm{C}$, respectively, while that of PP/IFR composite containing $1 \mathrm{wt} \%$ sepiolite is $13.9 \mathrm{wt} \%$. This illuminates that sepiolite could promote the char formation of the PP/IFR composites.

\subsection{Morphology analysis of the char residue}

The morphology of the residual char formed after cone calorimeter testing is investigated by scanning electron microscopy (magnification 500x). Figures $5 \mathrm{a}$ and $5 \mathrm{~b}$ present the SEM photographs of the outer char of the PP/IFR composite and PP/IFR/ SP $1 \%$ composite, respectively. As shown in Figure $5 \mathrm{a}$, it is observed that the char is loose and

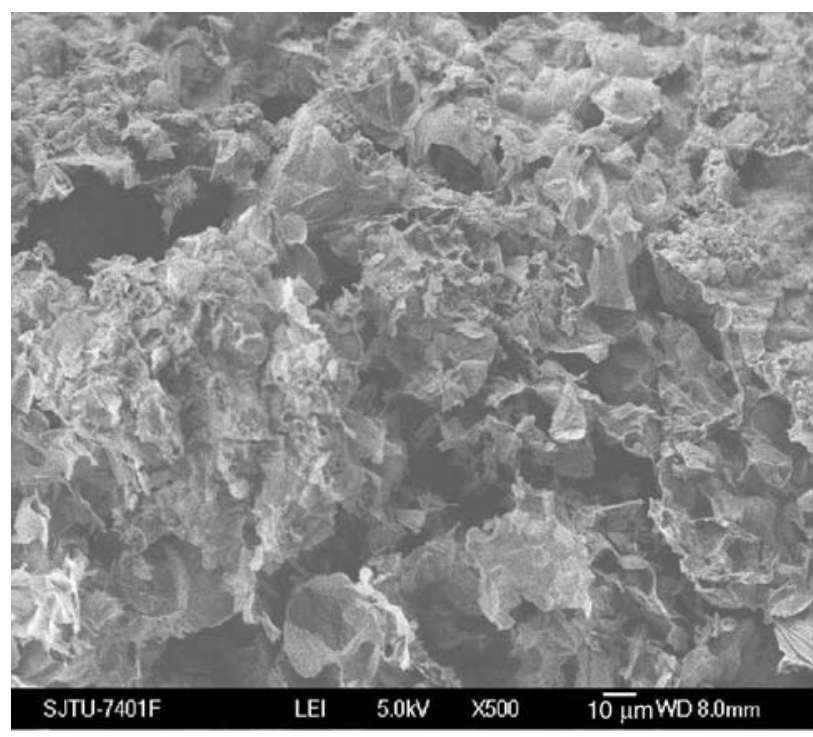

a)

Figure 5. SEM micrographs of PP/IFR char residue with and without sepiolite: (a) PP/IFR composite, 500×; (b) PP/IFR
24\%/SP 1\% composite, 500x

Figure 5. SEM micrographs of PP/IFR char residue with and without sepiolite: (a) PP/IFR composite, 500x; (b) PP/IFR
24\%/SP 1\% composite, 500x porous, so it cannot provide the good flame shield for the underlying material. Comparing Figure $5 \mathrm{~b}$ with Figure 5a, it is found that the char of the PP/ IFR/SP $1 \%$ composite is more homogenous than that of the PP/IFR composite. Moreover, the addition of sepiolite also seems to reinforce the char barrier, keeping it more resistant against the disintegrating effect of the bubbles evolved. So the char layer with improved performance leads to the enhancement of flame retardancy.

\subsection{Microstructure characterization of carbonaceous charred layers}

Raman spectroscopy has been proven an effective method to investigate the carbonaceous char formed by combustion of polymers [37-39]. Figure 6 shows the Raman spectra of the char residues formed after cone calorimeter testing. The spectra of the char residues with or without sepiolite exhibit two broad bands around 1580 and $1350 \mathrm{~cm}^{-1}$, similar to the graphite-like species [40]. The first band ( $G$ peak) may be assigned to the $E_{2 g}$ vibrational mode (C-C vibrations). The band at $1350 \mathrm{~cm}^{-1}$ (D peak), the so-called defect band [41], is assigned to the $A_{1 g}$ vibrational mode and may be related to the structural organization of the carbonaceous matter. These results provided a positive evidence for the formation of the carbonaceous matter.

Tuinstra and Koening [42] found that the relative intensity ration $R$ of the $D$ peak to the $G$ peak is

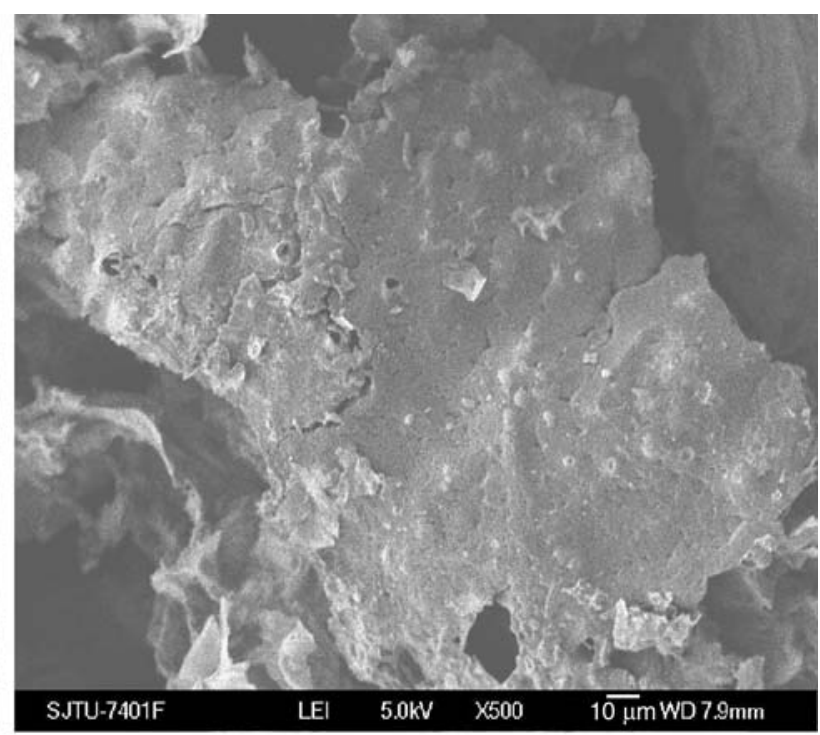

b) 


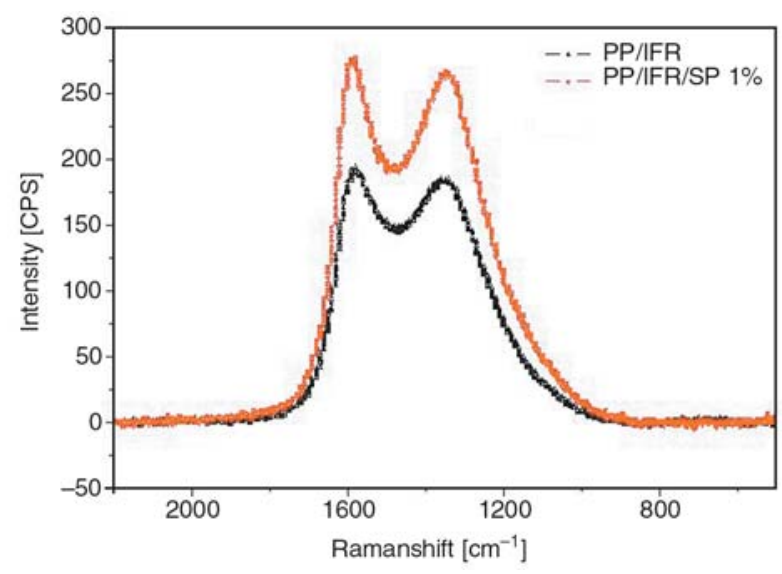

Figure 6. Raman spectra of chars produced during cone calorimeter experiments

inversely proportional to an in-plane microcrystalline size. From Figure 6, the relative intensity ration $R$ of the $D$ peak to the $G$ peak for PP/IFR/SP $1 \%$ composite ( $R$ is about 1.15 ) is higher than that of PP/IFR composite ( $R$ is about 1.07). That is to say, the size of carbonaceous microstructures from the PP/IFR/SP 1\% composite could be smaller than from the PP/IFR composite. Bourbigot et al. [43] believed that the higher protective shield efficiency was related to the smaller size of carbonaceous microstructures. Therefore, it is proposed that sepiolite or its pyrolytic products repress the increase of the carbonaceous micro-domain in size during burning, which leads to formation of more compact charred layers.

\subsection{Mechanical properties}

The mechanical properties of pristine PP and its flame retardant composites with different loading of sepiolite are listed in Table 4. Taking PP0 as an example, the addition of IFR by great amount into PP matrix reduces the tensile strength, elongation at break and notched Charpy impact strength, but oppositely for the Young's modulus, flexural strength and flexural modulus. An explanation for the reduction in elongation at break may be the for- mation of microvoids due to debonding of clay fibres from the polymer matrix upon failure. Comparing sample PP0 with the samples PP1, PP3 and PP4, adding sepiolite into PP/IFR system does not influence the tensile strength, flexural strength and elongation at break very much. However, Young's modulus and flexural modulus for the samples PP1, PP3 and PP4 are increased with increasing sepiolite content, probably because the rigid needle-like sepiolite in PP matrix directly enhanced the stiffness of flame retardant composites. At the same time, notched Charpy impact strength at $23^{\circ} \mathrm{C}$ for the samples PP1, PP3 and PP4 is slightly increased with increasing sepiolite content.

\section{Conclusions}

Flame-retardant system composed of sepiolite and IFR system (ammonium polyphosphate modified with aminosilane coupling agents and combined with melamine and dipentaerithritol) was processed by melt compounding to flame retard PP resin. The LOI, UL94 test results showed that sepiolite had a significant influence on flame retardancy and LOI value reached $36.0 \%$ with loading of $1.0 \mathrm{wt} \%$ sepiolite at the total amount of additives kept constant at $25 \mathrm{wt} \%$. Besides, the PP/IFR composites could pass UL $94 \mathrm{~V}-0$ rating with 1-2 wt\% sepiolite loading. The TGA results showed that sepiolite enhanced the thermal stability of PP/IFR composite and played a role of promoting the formation of char layer. From the results of cone calorimeter tests, sepiolite had obvious effects on CONE data, such as decreasing the heat release rate (HRR), the total heat release (THR), the average specific extinction area (av-SEA) and the average mass loss rate (avMLR) during combustion. By the analysis of the morphology and microstructures of char residue by the LRS and SEM, it was revealed that the synergistic effects between sepiolite and IFR on flame retardance was attributed to the improvement in building a reinforced and homogeneous char bar-

Table 4. Mechanical properties of pristine PP and its flame retardant composites

\begin{tabular}{|l|c|c|c|c|c|}
\hline \multicolumn{1}{|c|}{ Sample code } & PP & PP0 & PP1 & PP3 & PP4 \\
\hline Tensile strength $[\mathrm{MPa}]$ & $32.4 \pm 0.6$ & $29.3 \pm 0.4$ & $30.2 \pm 0.4$ & $29.8 \pm 0.3$ & $29.7 \pm 0.6$ \\
\hline Elongation at break [\%] & $32.2 \pm 2.1$ & $10.1 \pm 0.4$ & $8.8 \pm 0.2$ & $9.1 \pm 0.4$ & $9.2 \pm 0.4$ \\
\hline Young's modulus $[\mathrm{MPa}]$ & $456 \pm 37.8$ & $670 \pm 80.4$ & $738 \pm 83.6$ & $755 \pm 38.5$ & $768 \pm 37.8$ \\
\hline Flexural strength $[\mathrm{MPa}]$ & $38.9 \pm 1.0$ & $44.9 \pm 0.5$ & $46.1 \pm 0.9$ & $45.4 \pm 0.4$ & $45.8 \pm 1.0$ \\
\hline Flexural modulus $[\mathrm{MPa}]$ & $1280 \pm 47.6$ & $1458 \pm 17.8$ & $1540 \pm 17.3$ & $1545 \pm 17.4$ & $1589 \pm 27.6$ \\
\hline Notched charpy impact strength $23^{\circ} \mathrm{C}\left[\mathrm{kJ} / \mathrm{m}^{2}\right]$ & $6.1 \pm 0.6$ & $2.5 \pm 0.3$ & $2.7 \pm 0.2$ & $2.8 \pm 0.3$ & $3.0 \pm 0.3$ \\
\hline
\end{tabular}


rier on the surface of the burning composites. In addition, the rigid needlelike sepiolite in PP matrix directly enhanced the stiffness of flame retardant composites and improved the Young's modulus and flexural modulus.

\section{References}

[1] Lewin M., Endo M.: Catalysis of intumescent flame retardancy of polypropylene by metallic compounds. Polymers for Advanced Technologies, 14, 3-11 (2003). DOI: $\underline{10.1002 / p a t .265}$

[2] Du B., Guo Z., Fang Z. P.: Effects of organo-clay and sodium dodecyl sulfonate intercalated layered double hydroxide on thermal and flame behaviour of intumescent flame retarded polypropylene. Polymer Degradation and Stability, 94, 1979-1985 (2009). DOI: 10.1016/j.polymdegradstab.2009.07.024

[3] Xing W. Y., Song L., Lu H. D., Hu Y., Zhou S.: Flame retardancy and thermal degradation of intumescent flame retardant polypropylene with MP/TPMP. Polymers for Advanced Technologies, 20, 696-702 (2009). DOI: $\underline{10.1002 / \text { pat.1335 }}$

[4] Zhang M., Ding P., Qu B. J.: Flammable, thermal, and mechanical properties of intumescent flame retardant PP/LDH nanocomposites with different divalent cations. Polymer Composites, 30, 1000-1006 (2009). DOI: $10.1002 / \mathrm{pc} .20648$

[5] Liu Y., Feng Z. Q., Wang Q.: The investigation of intumescent flame-retardant polypropylene using a new macromolecular charring agent polyamide 11 . Polymer Composites, 30, 221-225 (2009). DOI: $10.1002 / \mathrm{pc} .20555$

[6] Li B., Xu M. J.: Effect of a novel charring-foaming agent on flame retardancy and thermal degradation of intumescent flame retardant polypropylene. Polymer Degradation and Stability, 91, 1380-1386 (2006). DOI: $10.1016 /$ j.polymdegradstab.2005.07.020

[7] He Q. L., Lu H. D., Song L., Hu Y., Chen L. J.: Flammability and thermal properties of a novel intumescent flame retardant polypropylene. Journal of Fire Sciences, 27, 303-321 (2009).

DOI: $10.1177 / 0734904109100182$

[8] Song P. A., Fang Z. P., Tong L. F., Xu Z. B.: Synthesis of a novel oligomeric intumescent flame retardant and its application in polypropylene. Polymer Engineering and Science, 49, 1326-1331 (2009). DOI: $10.1002 /$ pen. 21153

[9] Wang X. L., Song Y., Bao J. C.: Synergistic effects of nano- $\mathrm{Mn}_{0.4} \mathrm{Zn}_{0.6} \mathrm{Fe}_{2} \mathrm{O}_{4}$ on intumescent flame-retarded polypropylene. Journal of Vinyl and Additive Technology, 14, 120-125 (2008).

DOI: $10.1002 / \mathrm{vnl} .20152$
[10] Demir H., Arkis E., Balköse D., Ülkü S.: Synergistic effect of natural zeolites on flame retardant additives. Polymer Degradation and Stability, 89, 478-483 (2005).

DOI: $10.1016 / j . p o l y m d e g r a d s t a b .2005 .01 .028$

[11] Tang Y., Hu Y., Li B. Q., Liu L., Wang Z. Z., Chen Z. Y., Fan W. C.: Polypropylene/montmorillonite nanocomposites and intumescent, flame-retardant montmorillonite synergism in polypropylene nanocomposites. Journal of Polymer Science Part A: Polymer Chemistry, 42, 6163-6173 (2004).

DOI: $10.1002 /$ pola.20432

[12] Tang Y., Hu Y., Wang S. F., Gui Z., Chen Z. Y., Fan W. C.: Intumescent flame retardant-montmorillonite synergism in polypropylene-layered silicate nanocomposites. Polymer International, 52, 1396-1400 (2003). DOI: $\underline{10.1002 / \text { pi.1270 }}$

[13] Wei P., Hao J. W., Du J. X., Wang J. Q.: An investigation on synergism of an intumescent flame retardant based on silica and alumina. Journal of Fire Sciences, 21, 17-28 (2003). DOI: $10.1177 / 0734904103021001002$

[14] Wu Q., Qu B. J.: Synergistic effects of silicotungistic acid on intumescent flame retardant polypropylene. Polymer Degradation and Stability, 74, 255-261 (2001).

DOI: $10.1016 / \mathrm{S} 0141-3910(01) 00155-0$

[15] Wu J., Hu Y., Song L., Kang W. J.: Synergistic effect of lanthanum oxide on intumescent flame-retardant polypropylene-based formulations. Journal of Fire Sciences, 26, 399-414 (2008). DOI: $\underline{10.1177 / 0734904108091990}$

[16] Li Y. T., Li B., Dai J. F., Jia H., Gao S. L.: Synergistic effects of lanthanum oxide on a novel intumescent flame retardant polypropylene system. Polymer Degradation and Stability, 93, 9-16 (2008). DOI: 10.1016/j.polymdegradstab.2007.11.002

[17] Wang X. L., Song Y., Bao J. C.: Synergistic effects of nano- $\mathrm{BaWO}_{4}$ on intumescent flame-retarded polypropylene. Polymer-Plastics Technology and Engineering, 48, 621-626 (2009). DOI: $10.1080 / 03602550902824465$

[18] Wei P., Li H. X., Jiang P. K., Yu H. Y.: An investigation on the flammability of halogen-free fire retardant PP-APP-EG systems. Journal of Fire Sciences, 22, 367-377 (2004). DOI: $\underline{10.1177 / 0734904104042437}$

[19] Chen X. L., Jiao C. M., Wang Y.: Synergistic effects of iron powder on intumescent flame retardant polypropylene system. Express Polymer Letters, 3, 359365 (2009).

DOI: $10.3144 /$ expresspolymlett.2009.45 
[20] Zhang P., Song L., Lu H. D., Hu Y., Xing W., Ni J., Wang J.: Synergistic effect of nanoflaky manganese phosphate on thermal degradation and flame retardant properties of intumescent flame retardant polypropylene system. Polymer Degradation and Stability, 94, 201-207 (2009).

DOI: 10.1016/j.polymdegradstab.2008.11.004

[21] Liu Y., Wang Q.: Catalytic action of phospho-tungstic acid in the synthesis of melamine salts of pentaerythritol phosphate and their synergistic effects in flame retarded polypropylene. Polymer Degradation and Stability, 91, 2513-2519 (2006).

DOI: 10.1016/j.polymdegradstab.2006.03.009

[22] Chen X. L., Jiao C. M.: Synergistic effects of hydroxy silicone oil on intumescent flame retardant polypropylene system. Journal of Polymer Research, 16, 537543 (2009).

DOI: $10.1007 / \mathrm{s} 10965-008-9257-4$

[23] Yang D. D., Hu Y., Song L., Nie S. B., He S. Q., Cai Y. B.: Catalyzing carbonization function of $\alpha-\mathrm{ZrP}$ based intumescent fire retardant polypropylene nanocomposites. Polymer Degradation and Stability, 93, 2014-2018 (2008).

DOI: $10.1016 /$ j.polymdegradstab.2008.02.012

[24] Atikler U., Demir H., Tokatli F., Tihminlioglu F., Balköse D., Ülkü S.: Optimisation of the effect of colemanite as a new synergistic agent in an intumescent system. Polymer Degradation and Stability, 91, 1563-1570 (2006).

DOI: $10.1016 /$ j.polymdegradstab.2005.09.017

[25] Fontaine G., Bourbigot S., Duquesne S.: Neutralized flame retardant phosphorus agent: Facile synthesis, reaction to fire in PP and synergy with zinc borate. Polymer Degradation and Stability, 93, 68-76 (2008). DOI: 10.1016/j.polymdegradstab.2007.10.019

[26] Vannier A., Duquesne S., Bourbigot S., Castrovinci A., Camino G., Delobel R.: The use of POSS as synergist in intumescent recycled poly(ethylene terephthalate). Polymer Degradation and Stability, 93, 818-826 (2008).

DOI: $10.1016 /$ j.polymdegradstab.2008.01.016

[27] Marosi G., Márton A., Szép A., Csontos I., Keszei S., Zimonyi E., Tóth A., Almeras X., Bras M.: Fire retardancy effect of migration in polypropylene nanocomposites induced by modified interlayer. Polymer Degradation and Stability, 82, 379-385 (2003).

DOI: $\underline{10.1016 / \mathrm{S} 0141-3910(03) 00223-4}$

[28] Tartaglione G., Tabuani D., Camino G.: Thermal and morphological characterisation of organically modified sepiolite. Microporous and Mesoporous Materials, 107, 161-168 (2008).

DOI: 10.1016/j.micromeso.2007.04.020

[29] Ma J., Bilotti E., Peijs T., Darr J. A.: Preparation of polypropylene/sepiolite nanocomposites using supercritical $\mathrm{CO}_{2}$ assisted mixing. European Polymer Journal, 43, 4931-4939 (2007).

DOI: $\underline{10.1016 / j . e u r p o l y m j .2007 .09 .010}$
[30] Huang N. H., Chen Z. J., Wang J. Q.: Synergistic flame retardant effects between sepiolite and magnesium hydroxide in ethylene-vinyl acetate (EVA) matrix. Express Polymer Letters, 4, 227-233 (2010). DOI: $10.3144 /$ expresspolymlett.2010.29

[31] Marosfői B. B., Garas S., Bodzay B., Zubonyai F., Marosi G.: Flame retardancy study on magnesium hydroxide associated with clays of different morphology in polypropylene matrix. Polymers for Advanced Technologies, 19, 693-700 (2008).

DOI: $\underline{10.1002 / \text { pat. } 1153}$

[32] Marosfői B., Szabó A., Kiss K., Marosi G.: Use of organosilicone composites as flame retardant additives and coating for polypropylene. in 'Fire retardancy of polymers: New strategies and mechanisms' (eds.: Kandola K., Hull R.) The Royal Society of Chemistry, London, Vol 4, 49-58 (2008).

[33] Szabó A., Marosfői B., Anna P., Marosi G.: Complex micro-analysis assisted design of fire retardant nanocomposites- contribution to the nano-mechanism. in 'Fire retardancy of polymers: New Strategies and Mechanisms' (eds.: Kandola K., Hull R.) The Royal Society of Chemistry, London, Vol 4, 74-91 (2008).

[34] Demir H., Balköse D., Ülkü S.: Influence of surface modification of fillers and polymer on flammability and tensile behaviour of polypropylene-composites. Polymer Degradation and Stability, 91, 1079-1085 (2006).

DOI: 10.1016/j.polymdegradstab.2005.07.012

[35] Schartel B., Hull T. R.: Development of fire-retarded materials- Interpretation of cone calorimeter data. Fire and Materials, 31, 327-354 (2007).

DOI: $10.1002 /$ fam.949

[36] Bourbigot S., Le Bras M., Delobel R., Bréant P., Trémillon J-M.: Carbonization mechanisms resulting from intumescence-part II. Association with an ethylene terpolymer and the ammonium polyphosphatepentaerythritol fire retardant system. Carbon, 33, 283 294 (1995).

DOI: 10.1016/0008-6223(94)00131-I

[37] Bras M. L., Bourbigot S., Tallec Y. L., Laureyns J.: Synergy in intumescence- Application to $\beta$-cyclodextrin carbonisation agent in intumescent additives for fire retardant polyethylene formulations. Polymer Degradation and Stability, 56, 11-21 (1997). DOI: 10.1016/S0141-3910(96)00190-5

[38] Hillemans J. P. H. M., Colemonts C. M. C. J., Meier R. J., Kip B. J.: An in situ Raman spectroscopic study of the degradation of PVC. Polymer Degradation and Stability, 42, 323-333 (1993). DOI: 10.1016/0141-3910(93)90228-B

[39] Zhu S. W., Shi W. F.: Thermal degradation of a new flame retardant phosphate methacrylate polymer. Polymer Degradation and Stability, 80, 217-222 (2003).

DOI: $\underline{10.1016 / \mathrm{S} 0141-3910(02) 00401-9}$ 
[40] Bourbigot S., Le Bras M., Delobel R., Decressain R., Amoureux J. P.: Synergistic effect of zeolite in an intumescence process. Study of the interactions between the polymer and the additives. Journal of the Chemical Society, Faraday Transactions, 92, 34353444 (1996).

DOI: $10.1039 / F T 9969203435$

[41] Nakamizo M., Kammereck R., Walker Jr P. L.: Laser raman studies on carbons. Carbon, 12, 259-267 (1974).

DOI: $\underline{10.1016 / 0008-6223(74) 90068-2}$
[42] Tuinstra F., Koenig J. L.: Raman spectrum of graphite. The Journal of Chemical Physics, 3, 1126-1130 (1970).

DOI: $10.1063 / 1.1674108$

[43] Bourbigot S., Le Bras M., Delobel R., Decressain R., Amoureux J-P.: Synergistic effect of zeolite in an intumescence process: Study of the carbonaceous structures using solid-state NMR. Journal of the Chemical Society, Faraday Transactions, 92, 149-158 (1996). DOI: $\underline{10.1039 / F T 9969200149}$ 